\title{
We Need Change! The Interactive White Board in the EFL Context
}

\author{
Benmansour Souhila \\ Meziane Maliha Khadidja \\ Abou Bakr Belkaid University of Tlemcen \\ E-mail: benmansour.souhila@yahoo.com \\ m_meziane@mail.univ-tlemcen.dz
}

\section{Doi:10.5901/ajis.2013.v2n3p379}

\section{Abstract}

A noteworthy number of studies have explored the effect of using technology in language teaching and learning, in changing settings and contexts, and the majority accredit that the use of technology in language teaching and learning can promote enhancements in students' learning process. Currently, studies are no more searching whether ICTs can improve learning, but how an effective learning can benefit of particular technologies adopted in particular learning situation for achieving particular learning outcomes. In this context, Prensky (2007) states that "there is very little research as yet on technology's effectiveness in education, and much of that has been qualitative in nature". One such technology is the Interactive White Board (IWB) which is gaining particular attention for second and foreign language learners. The purpose of this research study is to determine the effect of the use of interactive whiteboards as an instructional tool on student engagement. Specifically, the desire is to see if student engagement in the learning process is increased while using an interactive whiteboard. It also attempts to investigate the following research questions: Does the use of the interactive whiteboard affect university students' engagement? How do teachers perceive the impact of interactive whiteboards on their students learning outcomes and on their classroom teaching practice? The findings will be discussed in relation to learning theories in addition to psycho-pedagogical outcomes for the use of the IWB in the EFL context.

Keywords: learning style; field of study; length of tertiary study; gender; age; learning language experience;

\section{Introduction}

Technology-enhanced education is becoming a progressively critical factor of teaching and learning languages and other subjects. The notion of Computer Assissted Language Learning (CALL) and the employ of new technology applications (e.g. multimedia, videoconferencing, electronic learning and on-line testing) influence the techniques used to learn and teach languages. Actually, digital technology can be used to facilitate the procedures wherein information can be brought and shared among teachers and learners.

A noteworthy number of studies have explored the effect of using technology in language teaching and learning in changing settings and contexts and the majority of these researches accredit that the employ of technology in language teaching and learning can promote enhancements in students' attainment and bloom the teaching and learning process. Today's technology has played an important role to uplift student's performances during the process of learning, and improves student's motivation to learn. It enhances also student's achievement and makes more genuine activities and materials. Technology is currently conceived as an impetus to embark on learning as it supports better interaction between teachers and students and amongst students themselves. In fact, technology stresses student's individual needs, and increases global understandings.

Current applications of information technology in educational contexts assent that new technology-based models of teaching and learning have the potential to bloom all through educational outcomes. Technology-based innovations provide particular challenges and opportunities via the trustworthy adoption of InformationCommunication Technologies (ICTs) and CALL applications whereby technology can be used to improve the learning environment for teachers and students simply because the goal is to create learning environments where students are actively engaged in the learning process. Nowadays, theories of learning highlight the significance of actively engaging students in the learning process and lately a variety of technologies has been designed to support active engagement in learning. One such technology is the Interactive White Board (IWB).

The current research investigates students' engagement with use of IWB in EFL context. The action research 
concerns 2 groups of students from Tlemcen university of Algeria, specialising in telecommunications, who have an English class once a week. The same lectures were conducted for both groups except that for one, it was with the help of the IWB. The findings will be analysed in relation to Students' engagement mainly.

\subsection{Why Using An Interactive White Board (IWB)?}

The first suggestion is set to foster oral skills especially in EFL contexts. Unlike the classical projection of the data showed on a computer screen; a display of data onto an Interactive Whiteboard is very different. Ahmad Al-Saleem (2012) argued that by means of an IWB; the user can easily navigate, browse, and surf from the board with no need to repeatedly go again to the computer and, as a consequence, turn his back to the class. The teacher can reflect and concentrate on his students' learning process the instead of the technology. This is extremely significant when employing Interactive White Boards to teach in EFL context.

Pennington (1996) remarked "that the computer can sometimes encourage a form of 'anti-social' behavior that leads to working in isolation from others". This is a usual disapproval of traditional teaching methods and is particularly pertinent to the foreign language teacher, who is asked to interact almost with the class. Through the use of the projector coupled with the Interactive Whiteboard projected to the whole class, a web document can streamline oral interaction when exchanging, for instance, perspectives, views and thoughts. Moreover, the use of the Interactive Whiteboard can be expanding to let the student himself, navigate the board in place of the teacher. The other students may direct him using the target language. The Interactive White Board joins people together, supports communication and develops students' apprehension of lesson material when they can physically interact with the lesson content by navigating text, and presenting projects on the board (Abraham and Liou 1991; Chapelle, 2003).

The value of the IWB is that it improves conversation. Becta study (2007) claimed that almost foreign language teachers realize that the Interactive White Board can aid certain kinds of conversations in that all students in the classroom may focus on the same point at the same time and conversation may then emerge from that. When the teacher is navigating from one item to another, he/she looks at and interacts with the class. The teacher can concentrate on the student's language production. The teacher can sit and participate with the students, when reading, discussing, interacting with each other. When new vocabulary is required, the teacher can type the new word into the keyboard, and then it will be showed on the board in an atmosphere of flexibility, and accessibility, captivating students' attention, engagement, and motivation. Just by writing the new word onto the board, the conversation may launch effectively. The students do not need to note down the word forthwith. By the end of the lesson, the reinforcement of the vocabulary can be done through demonstrating, underlying or circling. It can then be printed for the students and kept for the teacher.

The second suggestion of using an IWB in EFL classroom is because it delivers an authentic presentation of language.Campbell (2010) states that the IWB supports in presenting linguistic elements. The teacher can prepare a lesson in a Notebook file or Word Document, with the benefit of using the features of the Interactive Whiteboard by overwriting, highlighting or circling the items that he wants to underline.

The characteristics of the IWB can be explored when delivering authentic resources such as web sites permitting the instructor to make the learning process more engaging. Students can therefore ask questions, discover, learn about and assess, and analyze information throughout a diversity of multimedia sources on the Internet (text, images, sound files, video clips) that is why "the interactive whiteboard is a valuable learning tool" (Gerard et al, 1999).

Allen (2010) and Miller (2002) proposed in their researches the positive effect of authentic documents in language learning. With the employ of the IWB, the instructor cannot only surf and display a website; he/she can also explain, exemplify, and highlight specific linguistic and levels. This authentic exposure to a foreign language can enhance students' abilities of listening, speaking, reading, and writing a foreign language. In the shade of their studies, Allen(2010) and Miller (2002) discovered that the effective use IWB which stimulates students' interest and engagement in learning activities when lessons are more visually attractive because " students learn best through their leading senses, seeing, hearing and touching" (Walker,2003).

Active classrooms are multisensory and by using the IWB, educators can easily appeal to the three senses (sight, hearing, and touch), allowing students to interact with teaching materials in a way that boosts their individual skills (Ikan, 2011). Today's generations of students wait for presentation of information to be authentically and concreatly enhanced (Ishtaiwa, 2010). For example, it is easier to conceptualize the power of a volcano eruption when the information is enriched by an animation or a film clipping. Moreover, student engagement can be further enhanced by using an Interactive Whiteboard to gain even more attention by capturing particular parts of the process for highlighting or zooming in on specific point. 
A study by Gray et al (2005) demonstrated that the IWB provides teachers a variety of facilitated accessible ways of getting focus on grammatical features and that students realized that the use of the IWB positively effect their memorisation and writing skills. It also reported that when language lessons were effectively structered, with well-planned activities manipulated by a touch of a button, teachers promoted opportunities to encourage students' engagement. The study concludes that, even if teachers basically need additional preparation time, the IWB supports effective language teaching and in giving a diversity of visual, auditory and kinesthetic activities that can potentially affect students' academic achievement.

This study of the IWB in the foreign language classroom has led to an impression that the IWB is a very inventive and significant support for language learning. First of all, it gives a bridge that permits using the features of computers without interrupting communication - it even props it. Secondly, it may develop new kinds of learning processes to captivate students' engagement, motivation, collaboration, retention as major psycho-pedagogical factors that promote the process of a successful language teaching and learning process.

According to the available review of literature, it is evident that IWB can make a main impact on the learning and teaching process at different educational levels. The IWB might be regarded more as a practical aid to good pedagogy more willingly than as a whole pedagogy in itself for teaching languages.Basically, it is significant to understand how this positive influence can best be obtained in a particular educational context to acheive engaging, interesting, interactive lessons that captivate the interest and motivation of the students in pedagogically effective instruction.

Though the limited pertinent investigations claim that student language learning motivation and engagement behaviour may be positively impacted by the employ of the IWB, teachers should adapt their pedagogy when preparing lessons and delivering instructions although the use of this innovative technological tool.

\section{Matching the New Technology to Existing Pedagogy: IWB in Practice}

The purpose of this action research study is to determine the effect of the use of interactive whiteboards as an instructional tool on student engagement. Specifically, the desire is to see if student engagement in the learning process is increased while using an interactive whiteboard to deliver instruction enquiring: Does use of the interactive whiteboard affect university student engagement? How do teachers perceive the impact of interactive whiteboards on their students learning outcomes and on their classroom teaching practice?

This study will be conducted during the first semester of the academic year 2012-2013 in Tlemcen University (Algeria) for a group of 40 students majoring in 2nd year technical stream during their lectures of English language. In order to collect data and to check students' engagement and behaviours, questionnaires were delivered to a sample of 40 students enquiring about the EFL lectures when done; with and without the Interactive Board. Therefore, direct and systematic observations have been conducted weekly, employing an 'at-task' observation checklist to measure positive behaviour and attitude, and 'off-task'one for negative behaviour and attitude performance as an indicator of students' engagement. Data will be summarised by means of descriptive statistics, arranged into tables. Collected date has been organised for qualitative interpretation and analysis.

At-task behaviors comprise the facts of paying attention to the instruction, interacting verbally on the subject matter, participating in the given lesson activities, collaborating with classroom dealings, listening to instructions, making eye contact with the task or teacher, and seeking teacher help in the suitable way. Conversely, Off-task behaviors, were identified as showing disturbing behavior, being turned around in the seat, doing schoolwork other than that assigned or other non-subject-connected activity, being out of the seat, head down on desk, making noises or talking out.

Teacher attitude toward using the whiteboard as a means of delivering instruction and presenting the lessons is measured using a modified version of the Teachers' Attitudes toward Information Technology instrument (Koenraad, 2008). In addition, attitude questionnaires are completed by the two teachers in order to determine why they choose to use the IWB as a means of delivering instruction, as well as why they chose particular methods of using the whiteboard.

The data collected from observations and questionnaires are analysed to determine the level to which students are engaged during the lesson being taught using the whiteboard. The results are then compared to the data collected on the record of whiteboard to determine if there is a connection between the levels at which students were engaged as well as motivated to learn and the use of IWB as a technological device of lessons delivering and presentation. The teachers' observations and questionnaire results are analyzed to determine teacher attitudes toward using the whiteboard as an instructional and presentation tool. 


\subsection{Outcomes and Outlooks}

Informants indicated that they appreciated the integration of such technological tool in the educational settings. This was reflected in the mean scores where $80 \%$ informants responded that they much more enjoyed learning when the teacher used the Interactive Whiteboard to deliver instructions and present English language lectures. This was shown while 80\% of informants affirmed that they had fun and $70 \%$ stated that they concentrated better when the IWB was used and that they enjoyed using it in the classroom .Informants' feedback with a score of $75 \%$ showed that students were interested in the integration of the IWB as they were curious on how to use this technological tool. While for engagement, $85 \%$ of the informants confirmed that they were motivated to learn with the IWB and that their level of motivation was increased when the IWB was used in the classroom. $70 \%$ of students states that they felt deeply engaged and interested when the IWB was integrated in English language class.

On students' participation in a learning environment in which the IWB was integrated, $60 \%$ of the informants considered that the level of their participation in lessons presentations and activities was increased when the IWB was used because their felt motivated and involved in classroom activities. These significant results confirmed the finding of several studies showing that there is a positive relationship between students' motivation and participation that can facilitate the learning success. Students' full participation is also said to promote higher motivation and engagement to learn. This finding also indicated that the interaction with the IWB and between students and teacher fosters students' engagement and promotes much more participation in the teaching-learning process. This is extremely important because it derives from what seems to be a traditional mode of instruction in university institutions, where one person talks and the others listen and that students are perceived as passive listeners and receivers of information. Informants reported that during the English language lessons where the IWB was used as a tool for delivering instruction and presenting data, students were actively engaged to learn, exchange information, participate, interact and communicate in the classroom.

On students' interaction in classroom setting where the IWB was used, $65 \%$ of students believe that the use of IWB helps them interact with the digital screen, with peers and also with the teacher, exchanging knowledge and ideas.

The use of the IWB and sudents' retention is the focus of the next questions where $50 \%$ of informants demonstrated that the use of Interactive Whiteboard help students retain information which goes with the findings usually reported in IWB-use literature. For example, the use of videos or audios helps students to store information effectively and retrieve it rapidly. In this regard, the present study demonstrates that IWB influenced the nature of resource presentation which can potentially affect the development of thinking skills and retention of information. Such findings definitely have positive implications on the design of lessons activities to help students recall information.

These findings support results from other studies which ascertained that students learning via the IWB are more mindful and have greater motivation to learn. In addition, this study brings out that presenting learning material using multimedia clarifies the material and improves learning. Below is a graph representation:

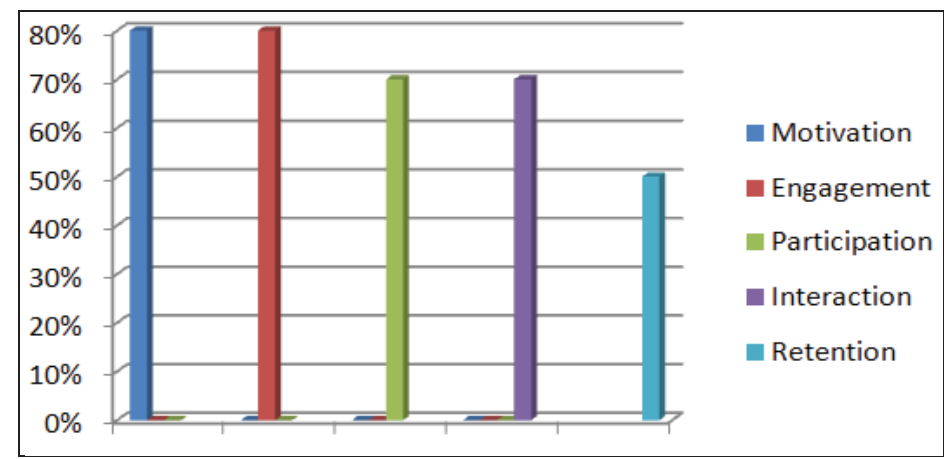

Fig.1: ranking of Students' Engagement Behaviour with the IWB

The attempt of this piece of research that is reported in this project is an initial study of the admission of "smart classrooms "and IWBs to the Algerian pedagogical policy and was conducted as a pilot with technology students at the Faculty of Technology in Tlemcen University for about one academic semester. Findings from the study advocate 
research conducted worldwide on the effect of implementing IWBs on learning and instruction. The objective of this action research study is to determine the effect of the use of the Interactive Whiteboard as an instructional tool on student engagement. Purposely, the study seeks to find out if student engagement in the learning process is increased while using the Interactive Whiteboard in classroom instruction and presentation.

Findings in this study reveal greater motivation in student learning and enthusiasm for students' use of IWB as part of the learning material. The results divulge a high level of satisfaction with most features of the digital board and its implementation in the classroom. In this research, classroom observations brought into focus the IWB's ease of demonstrations presentation appeals to senses (sight, hearing, and even touch), when students interact with the Interactive Whiteboard that address diverse learning styles and the critical thinking. The benefits of the Interactive Whiteboard lie in its ability to use web sites and display audio clips, and movies at the touch of a button. The incorporation of the IWB also appeals to teachers who aim at developing interactive instructions.

Consistent with other studies that identify positive students' response to technology in education (Brown, 2007; Swan, 2008; Betcher, 2009; Winzenried, 2010; Ikan, 2011) the findings of this study reveal that student attitudes toward learning with the IWB are mostly positive. Students' responses to the survey questionnaire show that they have greatly enjoyed the use of the IWB in classroom instruction and presentation. In fact, students express their appreciation of IWB's ability to support interaction and participation, individual engagement and improved motivation. In addition to the greater enjoyment of learning, students recognize the value and the effect of the use of theIWB on their learning process, mainly on greater understanding of the material, greater interest and engagement in the learning process that is also shown in their active participation in the lessons.

All through the interview, the interviewee teachers report that in spite of the difficulty of devoting extra time to preparing technology based lessons, the upside is greater student interest, motivation, and focus, support for different learning styles (aural and visual), and materials that are more effectively adjusted to students with varying abilities, planning a better lesson, presenting the learning material more easily, and an impression that that teachers are more upto-date. From the teachers' responses, it appears that instruction using technology in general is more professional and allows for better exposure to a wide variety of resources and assures more updated instruction.

In order to acheive these objectives, the following three conditions should be reflected upon:

- The will to develop and use the technology. With regard to this purpose, such investigations will contribute to convince decision makers of the appealing pedagogic benefit of new materials and approaches to teaching and learning.

- The change of thinking concerning the way of constructing classroom activities. This stept is fundamental to develop effective learning and instruction and to adapt the standardized methods and techniques often used in the teaching/learning process.

- The reflection upon the change. Though it is extremely significant to suggest a change in the field of edcation, it is critical to assess that change. The fact of integrating technological tools for instructions does not necessarily lead to prosperity in the quality of instruction and learning alike. The change should address learning materials, approaches and techniques of instructions adequate to different situations. An instance of this appears in the comparison study by Walker (2003), in which a group of high school students who learned abstract concepts in chemistry using the IWB got lower scores in comparison to a group that learned in the traditional way. These findings point out that, sometimes learning with technology in general, and with IWB in particular, can be regarded as a game, while during times of stress, the technology is put aside and educators go again to the traditional "teaching to the test".

\section{Conclusion}

The cornerstone of this research work was to analyse the educational value of the IWB's use in the university context of English language learning. Two main themes come out from the analysis of the information. The first is students' perception of the significance of IWB ability to promote interaction, participation, personal engagement and improved motivation which are regarded as positive factors used to determine student engagement for learning. The study highlights university students' need for and enthusiastic attitude to the Interactive Whiteboard and its creative teaching methodologies.

The second finding is that students also appreciated the IWB learning capacities and recognised its effectiveness in enhancing their learning of English language. More particularly, they realised its role in memorising and effective retention thanks to its multi- dimensional features. 
This study also spotlights the process the students' feedback and shows critical conceptions of student needs and perceptions of successful learning. From students' perspectives, this has also been considered to be critical in increasing motivation, engagement and effective learning.

Reflections on the findings will also allow teachers to further improve the pedagogical practice considering the research findings. For example, it will facilitate teachers 'design of interactive activities; to refine and develop a variety of IWB lessons and presentations to enhance different language skill.

This study took place in Tlemcen University where the demand for English language teaching with the use of technology is very appealing, as stated in the research of Meziane, M.K (2011). In addition to the current study on IWB, this constitutes a promising example of successful implantation of ICT in emerging countries.

\section{References}

Allen, A. (2010). Interactive Whiteboard Evaluation. Retrieved May 25, 2013,from www.mirandanet.ac.uk/pubs/smartboard.htm.

Al-Saleem, B. I. A. (2012). The interactive whiteboard in English as a foreign language (EFL) classroom. European Scientific Journal, 8(3).

Betcher, C., \& Lee, M. (2009). The interactive whiteboard revolution: Teaching with IWBs. Aust Council for Ed Research.

Campbell, C., \& Martin, D. (2010). Interactive whiteboards and the first year experience: Integrating IWBs into pre-service teacher education. Australian Journal of Teacher Education, 35(6), 5.

Gérard, F., \& Widener, J. (1999). A SMARTer way to teach foreign language: The SMART board interactive whiteboard as a language learning tool. Retrieved August, 23, 2010.

Gray, C., Hagger-Vaughan, L., Pilkington, R., \& Tomkins, S. A. (2005). The pros and cons of interactive whiteboards in relation to the key stage 3 strategy and framework. Language Learning Journal, 32(1), 38-44.

Ishtaiwa, F. (2010). Asynchronous discussion board in the program of Professional Diploma in Teaching: Perceptions of pre-service information technology teachers. International Journal of Arts and Sciences, 3(17), 200-219.

Koenraad, A. L. M. (2008). Interactive Whiteboards in educational practice: the research literature reviewed.

Manny-lkan, E., Dagan, O., Tikochinski, T. B., \& Zorman, R. Using the Interactive White Board in Teaching and Learning-An Evaluation of the SMART CLASSROOM Pilot Project.

Meziane, M. K. (2011). Integrating ICT for The Global Understanding Program.Global Partners in Education Journal, $1(1), 30$.

Miller, D., \& Glover, D. (2002). The interactive whiteboard as a force for pedagogic change: The experience of five elementary schools in an English Education Authority. Information Technology in Childhood Education Annual,2002(1), 5-19.

Miller, D., Brown, A., \& Robinson, L. (2002). Widgets on the Web Using Computer-Based Learning Tools. Teaching Exceptional Children, 35(2), 24-28.

Pennington, M. C. (1996). The power of CALL. Athelstan Publications.

Prensky, M. (2007). How to teach with technology: Keeping both teachers and students comfortable in an era of exponential change. Emerging technologies for learning, 2(4).

Swan, K., Schenker, J., \& Kratcoski, A. (2008, June). The effects of the use of interactive whiteboards on student achievement. In World Conference on Educational Multimedia, Hypermedia and Telecommunications (Vol. 2008, No. 1, pp. 3290-3297).

Walker, D. (2003). Quality at the Dockside. TES Online, 3, 66-67.

Winzenried, A., Dalgarno, B., \& Tinkler, J. (2010). The interactive whiteboard: A transitional technology supporting diverse teaching practices. Australasian Journal of Educational Technology, 26(4), 534-552. 